\title{
Second "Nano and Giga Challenges in Microelectronics" Conference Set for September 2004 in Cracow
}

Microelectronics technologies have reached the stage in their development where the ultimate miniaturization of electronic devices is approaching atomic dimensions, the interconnect bottleneck is posing a limit to circuit speeds, new materials are being introduced into microelectronic manufacturing at an unprecedented rate, and alternative technologies to mainstream complementary metal oxide semiconductors (CMOSs) are being considered. As a combination of today's microelectronics, tomorrow's nanoelectronics, and the future's molecular electronics, a series of conferences on Nano and Giga Challenges in Microelectronics (NGCM) is being launched. Following the inaugural summer school and symposium held in Moscow in 2002 (NGCM2002), the second biennial meeting will be held in Cracow, Poland, September 13-17, 2004, hosted by Jagiellonian University.

The meeting opens with a two-day summer school, followed by the three-day symposium. The summer school provides an overview of the current status of the field and offers plenary tutorial lectures and panel discussions involving speakers and attendees. The symposium includes plenary talks in the mornings, followed by oral and poster presentations in the afternoons. Evening sessions will focus on technology trends and opportunities for collaboration.

Academic and industrial researchers are invited to present tutorial, expository, and original research papers dedicated to scientific and advanced technology problems related to the ultimate merge of micro- and nanoelectronics in the following areas:

- Atomic-scale design: theory and experiment;

- Bio- and molecular electronics;

- Highest-frequency electronics;

- Fabrication of nanodevices;

- Magnetic materials and spintronics;

- Materials and processes for integrated and subwave optoelectronics;

- New materials for gate and dielectrics in field-effect transistors;

- Nonsilicon materials and devices;

- Quantum effects in devices; and

- System design technologies.

The deadline for abstract submission is April 15, 2004. On-line registration, abstract submission, and updated information, including frequently asked questions (FAQs), are available on the meeting Web site at http:/ / asdn.net/ngcm2004.

Alternatively, for more information on the meeting program or general information, contact the program committee chair,

Anatoli Korkin, at Nano and Giga Solutions Inc., 1683 E. Spur St., Gilbert, AZ 85296 USA; tel./ fax 480-539-4754 and e-mail korkin@nanoandgiga.com. For more information on registration, contact Jan K. Labanowski, Science Computing Facility, 225 Nieuwland Science Hall, University of Notre Dame, Notre Dame, IN 46556 USA; e-mail jkl@asdn.net. For more information on accommodations, contact Jadwiga Rudzinska in Cracow at e-mail jadwiga@makolab.pl.

๑

$\circ$

$\circ$

$-$

c

ב

a

is

ᄀ

ข

7

$\oplus$

n

(4)

E

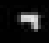

$\oplus$
Hall Measurement System $, \ldots,+, \ldots, \ldots, \ldots, \ldots, \ldots, \ldots, \ldots$ MMR's low cost. Tumbey Hall Elect Measurement. System provides user programuned compular contiolled measurement and data acquisition over a tamperature ranze of $-2000^{\circ} \mathrm{C}$ to $4300^{\circ} \mathrm{C}$ - whost the use of liquid nitrogen. The Jystem measures magneto rasistivily, four point regigsivity, sheet resistivity, sheet number, mobility. Hall coeflicient, and cartiat denally using the Fin der Paw and Hall measurument fecinicies.

\begin{tabular}{|c|c|}
\hline \multicolumn{2}{|c|}{ 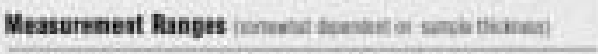 } \\
\hline Resistivity & 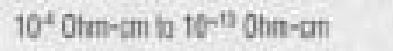 \\
\hline Carnier Mobility & tctit / val-set to $10^{-1}$ ont / voll-ses \\
\hline Carrier Density & $10^{3} \mathrm{~cm}^{-2}$ b $10^{+5} \mathrm{~cm}^{2}$ \\
\hline
\end{tabular}

For more informalion abost the Hall Eltect Measuitement System, contast Bob Pugh at $650 / 962-9620$ or toosenenticom. or vitit our web page at htip://ww.mint.com.

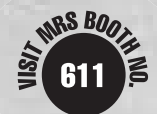

WMA MMR Technologies, Inc.

For more information, see http://advertisers.mrs.org 